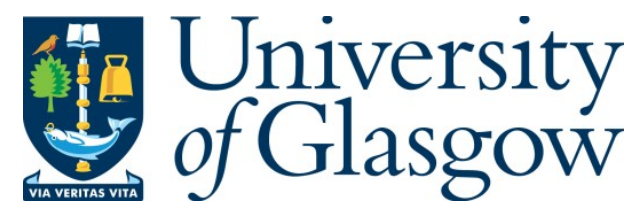

Lin, Z., Liu, X., Lao, L. and Liu, H. (2020) Prediction of two-phase flow patterns in upward inclined pipes via deep learning. Energy, 210, 118541.

(doi: 10.1016/j.energy.2020.118541)

This is the Author Accepted Manuscript.

There may be differences between this version and the published version. You are advised to consult the publisher's version if you wish to cite from it.

https://eprints.gla.ac.uk/222279/

Deposited on: 18 August 2020

Enlighten - Research publications by members of the University of Glasgow http://eprints.gla.ac.uk 


\title{
Prediction of Two-Phase Flow Patterns in Upward Inclined Pipes via Deep Learning
}

\author{
Zi Lin ${ }^{1}$, Xiaolei Liu²*, Liyun Lao33, Hengxu Liư \\ ${ }^{1}$ Department of Mechanical \& Construction Engineering, Northumbria University, Newcastle, NE1 8ST, United Kingdom \\ ${ }^{2}$ James Watt School of Engineering, University of Glasgow, Glasgow, G12 8QQ, United Kingdom \\ ${ }^{3}$ Centre for Thermal Energy Systems and Materials, Cranfield University, Cranfield, MK43 OAL, United Kingdom \\ ${ }^{4}$ College of Shipbuilding Engineering, Harbin Engineering University, Harbin, 150001, China
}

\begin{abstract}
The industrial process involving gas liquid flows is one of the most frequently encountered phenomena in the energy sectors. However, traditional methods are practically unable to reliably identify flow patterns if additional independent variables/parameters are to be considered rather than gas and liquid superficial velocities. In this paper, we reported an approach to predict flow pattern along upward inclined pipes $\left(0 \sim 90^{\circ}\right)$ via deep learning neural networks, using accessible parameters as inputs, namely, superficial velocities of individual phase and inclination angles. The developed approach is equipped with deep learning neural network for flow pattern identification by experimental datasets that were reported in the literature. The predictive model was further validated by comparing its performance with well-established flow regime forecasting methods based on conventional flow regime maps. Besides, the intensity of key features in flow pattern prediction was identified by the deep learning algorithm, which is difficult to be captured by commonly used correlation approaches.
\end{abstract}

Keywords: Flow pattern prediction; Two-phase flow; Deep learning.

\section{Introduction}

Accurate predictions of two-phase flow characteristics, including flow pattern identifications, are highly desired in various industrial sectors of energy, ranging from onshore/offshore hydrocarbon transportations [1] to water management [2], operations of multiphase reactors \& boilers [3], heat transfer [4], fuel cells [5,6], geothermal energy extraction [7,8], offshore wind turbines $[9,10]$ and photovoltaic cells $[11]$. The term of flow patterns is widely used to describe the featured spatial distribution of phases, occurring during multiphase flow in pipes. Gas-liquid two-phase flow is among the most commonly observed multiphase flows, which are often encountered in energy-producing and chemical processing [12]. For example, stratified gas-liquid flow is frequently observed in petroleum, natural gas and process industries [13]. In addition to stratified flows, in the offshore gas production and transportation systems, gas-liquid flows are transported from the seabed to the near surface areas, where the pipelines \& risers are often subject to slug flows. These flow patterns require advanced methods in

\footnotetext{
${ }^{*}$ Corresponding author, E-mail: Xiaolei.Liu@glasgow.ac.uk (XL)
} 
predicting and analysing the interaction between pipes and multiphase flows, which are of great importance for design and evaluating failures of the pipes [14]. In the energy-conversion process with multiphase reactor applied, the flow has the feature of chaotic bubbles and high turbulence, resulting in difficulties in establishing accurate models for the non-linear multiphase flow hydrodynamics [15]. To sum up, flow pattern prediction and identification are one of the fundamental issues in two-phase flow studies, which is essential to support industries for healthier economic design, better optimisation of operating conditions and enhanced assessment of safety.

Numerous experimental studies have been conducted to investigate flow patterns in both vertical and horizontal directions. One of the most widely accepted classifications of gas-liquid two-phase flow regimes in upward vertical pipes was suggested by Hewitt and Hall-Taylor [16], who categorized the basic flow patterns as bubble, slug, churn, and annular flows. Later, Taitel et al. [17] created corresponding models to identify the transition boundaries between the basic flow regimes above. For twophase horizontal flows, Barnea et al. [18] classified observed flow regimes into four major categories, named as stratified, intermittent, annular, and dispersed bubble. Comparing with vertical and horizontal flow studies, fewer investigations have been carried out on inclined two-phase flows. Barnea [19] proposed a unified model for flow pattern identification in inclined pipes, where flow regimes were defined for the whole range of upward and downward pipe inclinations. The predictive results were compared with experimental observations from Shoham [20], in which satisfying agreements were reached. In this investigation, the classifications of gas-liquid two-phase flow were defined into four major categories: stratified (containing stratified smooth and stratified wavy), Intermittent (containing elongated, slug and churn), annular (containing annular wavy and annular), and dispersed bubble or bubble flow. This is one of the earliest studies that covered flow pattern classification from shallow-inclined to near-vertical flows. Besides, Barnea et al. [18] presented experimental observations of flow regimes for air-water two-phase flow in pipes with inclination angles of $0.25 \sim 10^{\circ}$. The authors claimed that stratified flow did not appear while upward inclinations were higher than $10^{\circ}$. Oddie et al. [21] investigated two-phase flows in large diameter inclined pipes under a diameter of $15 \mathrm{~cm}$, where inclined angles varied from 0 (vertical) $\sim 92^{\circ}$. Detailed flow pattern maps were generated over water/gas, oil/water, and oil/water/gas systems. Zhang et al. [22] proposed a unified model that can be used for predictions of liquid holdup, slug characteristics, pressure gradient as well as flow patterns in upward and downward inclined pipes, validated by experimental observations [23].

The nature of the multiphase flow process has determined the challenges in accurate flow pattern identification. Unlike traditional methods, in recent years, many researchers have treated machine learning as a potential alternative in flow pattern forecasting [24] employing flow regime maps while the physical process of multiphase flows is too complicated [25]. It provides potential solutions in nonlinear systems and generates its own rules for learned examples. Deep learning neural 
network, which is a branch of machine learning, is a system that was inspired by biological neural networks. The structure of this type of machine learning model was built on an assembly of connected nodes named neurons, where data were transmitted from one neuron to another. These neurons could be aggregated into the input layer, hidden layers, and the output layer, linking through defined weights and biases. One of the earliest studies that applied machine learning algorithms on two-phase flow regime identification is proposed by Cai et al. [26], where an artificial neural network (ANN) model was tested to determine flow patterns in horizontal air-water flows. The ANN model was trained by stochastic features derived from turbulent absolute pressure signals under 366 measurements. The authors concluded that flow regimes identified by the network were consistent with visual observations. Hernández et al. [27] designed an ANN model to process conductivity probe signals for flow pattern classification. The authors claimed that a good agreement was achieved with visual flow regime maps. Rosa et al. [28] trained various machine learning models through instantaneous readouts of an electrical resistivity probe for flow pattern identification, using probabilistic neural network, radial basis functions, and multiple layer perceptrons. The inputs were taken from 73 vertical air-water two-phase flow tests while the output results can be single or multiple. All the tested machine learning algorithms performed equivalently with accuracies of $96 \sim 100 \%$. Santoso et al. [29] used Power Spectral Density (PSD) from pressure difference data as inputs to train ANN models for predicting flow patterns in horizontal flows, where accuracies of $98 \sim 100 \%$ were reached. Ghosh et al. [30] evaluated three machine learning models to capture flow regimes in vertical two-phase flow tests, where two conductivity probes were installed for input data collections. The authors recommended that the ANN model with back-propagation algorithm gives the best performance. Figueiredo et al. [31] suggested using ANN to overcome the drawback of present ultrasonic techniques in multiphase flow metering. The authors built an ANN model by extracting acoustic attenuation data as inputs from vertical oil-continuous multiphase flows, the accuracies of all observed flow regimes are above 80\%. Abbagoni and Yeung [32] used signals from an ultrasonic Doppler sensor as inputs to train an ANN model. The air-water two-phase flow under slug, elongated bubble, stratified-wavy and stratified flow patterns are tested against to a multilayer perceptron neural network, scoring accuracies of $87.5 \sim 95.8 \%$. Hanus et al. [33] recommended using signals from scintillation detectors in gamma-ray absorption as inputs for creating machine learning models. The two-phase experiments were performed through a horizontal pipeline with a diameter of $30 \mathrm{~mm}$. In total, six computational intelligence algorithms were tested, including single decision tree, K-means clustering algorithm, multilayer perceptron, probabilistic neural network, support vector machine, and radial basic function neural network. All the evaluated algorithms provided well-behaved recognition accuracies that are higher than 90\%. The experimental setup and the defined machine learning inputs/outputs in the investigations above are summarized in Table 1. Though various experimental conditions have been explored, all authors 
targeted at similar types of flow patterns. Besides, all machine learning models were trained by feeding input features generated from signals of advanced measuring instruments. 
Table 1 - Experimental setups and machine learning inputs/outputs in flow pattern identification from reviewed literature.

\begin{tabular}{|c|c|c|c|c|c|c|c|}
\hline References & $\begin{array}{c}\text { Pipe } \\
\text { diameter, } \mathrm{mm}\end{array}$ & Pipe orientation & Working fluids & $\begin{array}{c}\text { Superficial gas } \\
\text { velocity, } \mathrm{m} / \mathrm{s}\end{array}$ & $\begin{array}{l}\text { Superficial liquid } \\
\text { velocity, } \mathrm{m} / \mathrm{s}\end{array}$ & Machine learning inputs & Identified flow patterns (outputs) \\
\hline Cai et al. [26] & 50.8 & horizontal & air/water & $0.19 \sim 10.38$ & $0.71 \sim 3.33$ & $\begin{array}{l}\text { stochastic features derived from } \\
\text { turbulent absolute pressure signals }\end{array}$ & $\begin{array}{c}\text { bubbly, slug, plug, wavy, and } \\
\text { stratified }\end{array}$ \\
\hline Hernández et al. [27] & 50.8 & vertical & air/water & $0.0043 \sim 9.83$ & $0.031 \sim 2.51$ & conductivity signals & $\begin{array}{l}\text { bubbly, cap-bubbly, slug, churn- } \\
\text { turbulent, and annular }\end{array}$ \\
\hline Rosa et al. [28] & 26 & vertical & air/water & $0.1 \sim 30$ & $0.2 \sim 3$ & $\begin{array}{c}\text { instantaneous readouts of an electrical } \\
\text { resistivity prob }\end{array}$ & $\begin{array}{c}\text { bubbly, spherical cap, stable slug, } \\
\text { unstable slug, semi-annular, and } \\
\text { annular }\end{array}$ \\
\hline Santoso et al. [29] & 24 & horizontal & air/water & $0.085 \sim 3.20$ & $0.016 \sim 1.26$ & $\begin{array}{l}\text { Power Spectral Density (PSD) from } \\
\text { pressure difference data }\end{array}$ & stratified, plug, and slug \\
\hline Ghosh et al. [30] & 25.4 & vertical & air/water & $0.20 \sim 5.26$ & $0.0066 \sim 0.14$ & conductivity probe signals & slug, churn, annular, and flooding \\
\hline Figueiredo et al. [31] & $25.4 / 50.8$ & vertical & $\begin{array}{l}\text { oil/air/polyamide/ } \\
\text { sand/water }\end{array}$ & $0 \sim 0.37$ & $0.04 \sim 0.3$ & ultrasonic attenuation data & $\begin{array}{l}\text { dispersed bubbles, intermittent } \\
\text { flow, churn flow, and annular flow }\end{array}$ \\
\hline $\begin{array}{c}\text { Abbagoni and Yeung, } \\
{[32]}\end{array}$ & 50.8 & horizontal & air/water & $0.05 \sim 2.75$ & $0.004 \sim 2$ & ultrasonic signals & $\begin{array}{l}\text { slug, elongated bubble, stratified- } \\
\text { wavy, and stratified }\end{array}$ \\
\hline Hanus et al. [33] & 30 & horizontal & air/water & $1.33 \sim 2.67$ & $2.08 \sim 3.56$ & $\begin{array}{l}\text { signals from scintillation detectors } \\
\text { through gamma-ray absorption }\end{array}$ & $\begin{array}{l}\text { slug, plug, bubble, and transitional } \\
\text { plug-bubble }\end{array}$ \\
\hline
\end{tabular}


As presented in Table 1, most previous studies only considered cases of fixed flow inclinations in their machine learning models, either vertical or horizontal. The impact of varying inclined angles on flow regimes are not often considered. Besides, it is common to involve advanced measuring devices in experimental setups to obtain signals that are depending on flow regimes, such as scintillation detectors, electrical resistivity probe or ultrasonic transducers (see Table 1). Those signals/data have to be measured through certain instruments and are not available in general cases. Furthermore, there have been no quantitative evaluations of correlations, linear or nonlinear, between features and the predicted flow patterns. To fill the above knowledge gaps, the key contributions of this paper in flow pattern identification were summarised as follows:

- As flow inclinations can significantly influence flow behaviours, a predictive method without considering inclined angles will certainly limit its modelling capacities. Unlike previous studies, the current investigation explored the potentials of using deep learning for the gas-liquid two-phase flow pattern prediction with the variable of flow inclinations ranged from horizontal to upward vertical.

- In this study, to avoid using additional measuring instruments, only accessible parameters were considered as input features in the predictive model after precise feature selections, namely superficial velocity of water, superficial velocity of gas, and inclination angles, which made the proposed model more appropriate in industrial applications.

- Flow patterns have the characteristic of high nonlinearity in multiphase flow loops and are difficult to be signified using effortless equations/models. There has been no analysis regarding how different variables quantitatively influence flow regime classifications, although this is of great importance for application purposes. To this end, the current study directed deep learning algorithms to explore nonlinear correlations between the defined input features and the targeted flow regimes. The levels of significance of key flow variables in flow pattern prediction were also identified by the deep learning neural networks.

This paper is united as follows: Section 2 described selected experimental datasets and discussed how input features were nominated in designed deep learning neural networks. Also, the linear correlations of those features were explored by Pearson product-moment correlation coefficients. Section 3 presented the configuration of the designed deep learning model, including how weights, biases, and the activation function were initialized and updated in neural network layers. In section 4, based on the selected features and the deep learning structure, the predictive model was trained, tested and validated against experimental observations \& conventional flow regime maps. Besides, in this section, the nonlinearity correlations between inputs features and flow patterns were quantitatively defined by the deep learning model. Finally, conclusions were drawn in section 5. 


\section{Feature Engineering}

The essence of the proposed model in this paper starts from dealing with raw data and transforming the physical meanings of flow patter identification into numeric representation, which is often known as features [34]. This is one of the most vital steps in building any machine learning predictive model, as effectively selection of features is beneficial to improve the accuracy in deep learning and ultimately enhancing the model's quality [34]. Besides, ineffective features adding into the predictive model may lead to a negative impact on the output prediction [35]. Therefore, in this section, a comprehensive discussion will be put forward to select the optimal input candidates in deep learning based flow pattern prediction.

\subsection{Feature selection}

Existing experimental studies have proved that flow regimes highly depend on size \& orientation of the pipe, fluids' properties, and flow rates of each phase [36]. In this study, the relevant influencing factors of flow patterns are summarised in Table 2, which were categorised into independent and dependent parameters. In the independent group, some of those parameters are near-constant under a certain operating condition while the temperature is unchanging, such as density $\&$ viscosity of gas and liquid. Besides, if experiments were carried out in one location and through a certain flow loop, the roughness of pipes, pipe diameters, and gravity can be treated as constant values.

Table 2 - Influencing parameters of flow patterns in two-phase flows. Note that the selected features are highlighted in red.

\begin{tabular}{|c|c|}
\hline Independent parameters & Dependent parameters \\
\hline Density, $\rho_{l}, \rho_{g}$ & \multirow{2}{*}{ Reynolds number, $R e$} \\
\hline Viscosity, $\mu_{l}, \mu_{g}$ & \multirow{2}{*}{ Froude number, $F r$} \\
\hline Roughness of pipes, $\varepsilon$ & Holdup, $H_{L}$ \\
\hline Pipe diameter, $D$ & \multirow{2}{*}{ Pressure gradient, $\nabla p$} \\
\hline Inclination, $\theta$ & \\
\hline Gravity, $g$ & \\
\hline Operating temperature, $T$ & \\
\hline superficial velocity, $v_{s l}, v_{s g}$ & \\
\hline
\end{tabular}

In the dependent group, there are two dimensionless numbers that are often used to describe the characteristics of twophase flow, named Reynolds [37] and Froude [38] numbers, respectively. The Froude number deals with the relationship between gravity and inertial forces (see Eq. (1)), while the Reynolds number deals with the relationship between frictional and inertial forces (see Eq. (2)). In this paper, Reynolds and Froude numbers are not considered as they are the product of the superficial velocity of gas or liquid phase in combination with other constant values. Besides, pressure gradient [39] and holdup [40] are also dependent parameters of superficial velocities of gas \& liquid, which are not considered in this modelling work. 


$$
F r=\frac{v}{\sqrt{g\left(1-\frac{\rho_{g}}{\rho_{l}}\right) D}}
$$

where $F r$ is the Froude number; $v$ is the superficial velocity of gas or liquid phase, $\mathrm{m} / \mathrm{s} ; g$ is the gravitational constant, $\mathrm{m} / \mathrm{s}^{2} ; \rho_{g}$ is the gas density, $\mathrm{kg} / \mathrm{m}^{3} ; \rho_{l}$ is the liquid density, $\mathrm{kg} / \mathrm{m}^{3} ; D$ is the inside diameter of pipe, $\mathrm{m}$.

$$
R e=\frac{\rho v D}{\mu}
$$

where $R e$ is the Reynolds number; $\rho$ is the density of gas or liquid phase, $\mathrm{kg} / \mathrm{m}^{3} ; \mu$ is the viscosity of gas or liquid phase, $\mathrm{Pa} \cdot \mathrm{s}$.

Therefore, in the currently proposed deep learning model, only superficial velocities of air, superficial velocities of water, and inclination angles were selected as the input features, while flow patterns were chosen as the output variables. The selected features are the ones that are accessible and sensitive to flow regimes, avoiding any overfitting or underfitting in the learning process.

\subsection{Experimental dataset}

The selected datasets were extracted from the database created by Pereyra et al. [41], which was used to quantify the confidence level in air-water two-phase flow pattern prediction. The datasets were originally recorded by Shoham [42] in his research regarding flow pattern transition in inclined pipes. The experimental setup consisted of a pipe with a diameter of 50.8 $\mathrm{mm}$, where the upward inclined angles vary from $0^{\circ}$ to $90^{\circ}$. In total, 1952 groups of tests were carried out at atmospheric conditions. A more detailed explanation regarding experimental equipment and the procedure can be found in Barnea et al. [18].

Since correlations among selected features have a significant influence on flow patterns, they were graphically presented in Fig. 1 with the form of a scatter matrix. The histogram of each feature was displayed along the leading diagonal of the scatter matrix in Fig.1 a d, respectively. Variations of upward inclined angles were distributed in the range of $0 \sim 90^{\circ}$ (see Fig.1a). The water superficial velocities changed in the range of $0.0022 \sim 6.3 \mathrm{~m} / \mathrm{s}$ while the air superficial velocities varied from 0.016 to $40 \mathrm{~m} / \mathrm{s}$. Most numbers of tests were conducted during the superficial velocity intervals of $0 \sim 1 \mathrm{~m} / \mathrm{s}$ in water flow (see Fig.1b) and $0 \sim 5 \mathrm{~m} / \mathrm{s}$ in air flow (see Fig.1c), respectively. The classification of flow patterns was defined into dispersed bubble, stratified smooth, stratified wavy, annular, intermittent (containing elongated, slug and churn flow), and bubble (see Fig.1d). Under various operating conditions, the most commonly observed flow pattern was intermittent flow while the fewest detected flow regime was stratified smooth. Besides, as presented in the scatter matrix of Fig.1, it can be observed that flow patterns and input features are not simply linear related. 


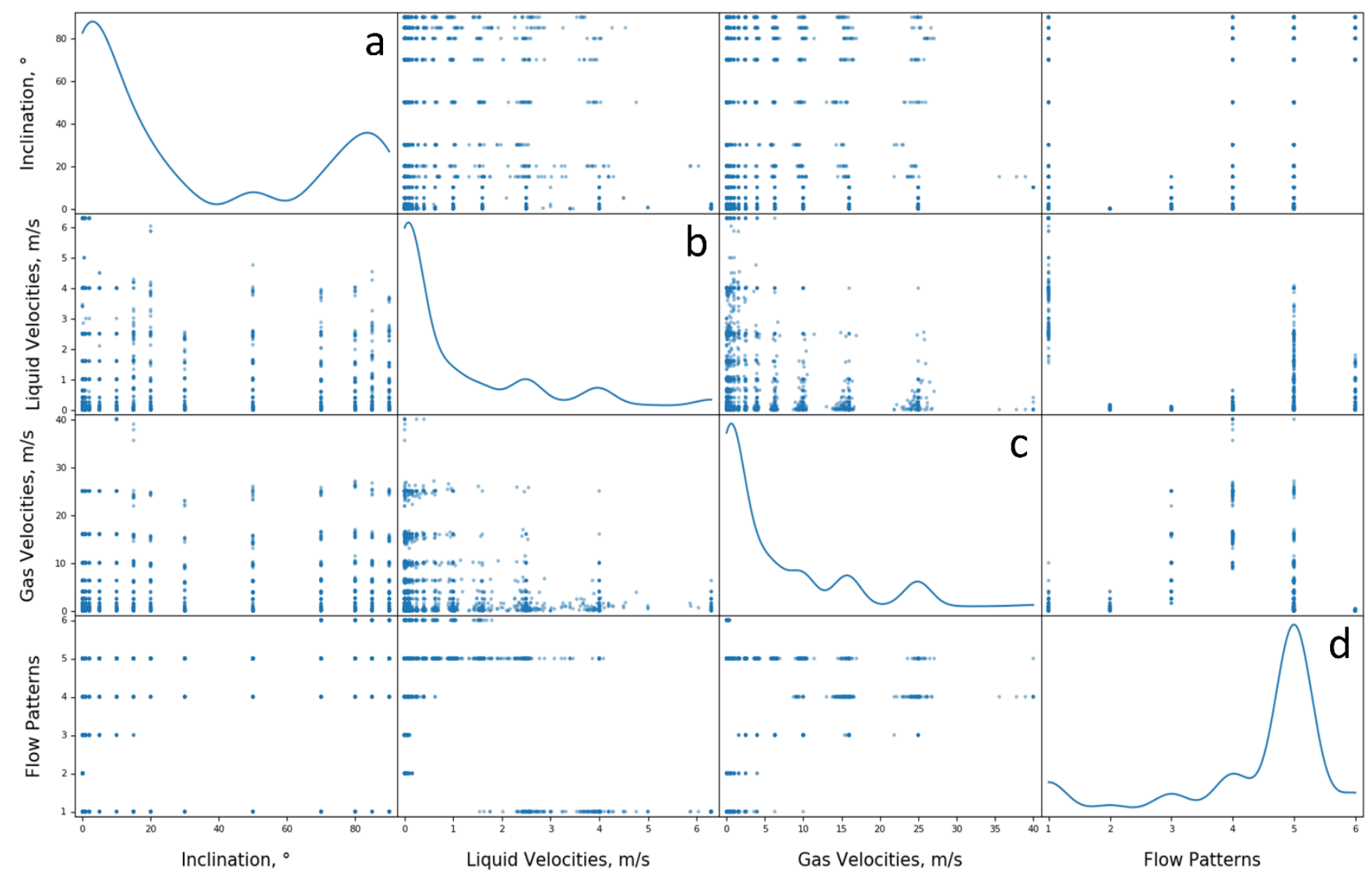

Fig. 1 - Scatter matrix of selected features in the experimental datasets, including inclination angles, superficial velocities of liquid, superficial velocities of air, and corresponding flow patterns; note that, the observed flow pattern categories were digitalized as 1 - dispersed bubble, 2 - stratified smooth, 3 - stratified wavy, 4 - annular, 5 - intermittent, and 6 - bubble in the subplot of (d).

\subsection{Correlation coefficients}

It is essential to discover and quantify the correlations between every pair of features in our dataset, which offers an initial quantitively analysis for feature reduction [43]. Before looking for correlations, flow patterns are required to be converted from categorical attribute to numerical attribute. This was realised through Scikit-Learn (a machine learning library of Python), where the observed flow pattern categories were digitalized as 1 - dispersed bubble, 2 - stratified smooth, 3 - stratified wavy, 4 - annular, 5 - intermittent, and 6 - bubble.

The Pearson product-moment correlation coefficients [44], which examine the linear relationship between two vectors in the form of the covariance matrix of the data [43], were applied in this section. More specifically, if two features of $X$ and $Y$ are measured on each of $n$ individuals to the database of $\left(X_{1}, Y_{1}\right) \sim\left(X_{i}, Y_{i}\right) \sim\left(X_{n}, Y_{n}\right)$, the correlation coefficients $(C)$ can be expressed as: 


$$
\begin{aligned}
& \bar{X}=\frac{1}{n} \sum_{i=1}^{n} X_{i} \\
& \bar{Y}=\frac{1}{n} \sum_{i=1}^{n} Y_{i} \\
& C=\frac{\sum_{i=1}^{n}\left\{\left(X_{i}-\bar{X}\right)\left(Y_{i}-\bar{Y}\right)\right\}}{\sqrt{\sum_{i=1}^{n}\left(X_{i}-\bar{X}\right)^{2}} \sqrt{\sum_{i=1}^{n}\left(Y_{i}-\bar{Y}\right)^{2}}}
\end{aligned}
$$

The Pearson product-moment correlation coefficients provided values between +1 and -1 , in which +1 and -1 are representing a perfect linear positive and negative correlation, respectively, while 0 indicates no linear relationship between variables. The other boundaries in measuring the relationships are divided by 0.3 and 0.7 . More specifically, for correlation coefficients between 0 and 0.3 , a week positive relationship can be concluded, and the assumption of a linear relationship is unreliable. Besides, correlation values between 0.3 and 0.7 form a moderate linear relationship while correlations fall into the range between 0.7 and 1 revealing that a well-founded linear relationship can be derived [44]. Based on Pearson's correlation and Eqs. (3) (5), values of correlation coefficients between variables are presented graphically for all features in flow pattern prediction with the form of the heat map (see Fig. 2).

As presented in Fig. 2, correlation coefficients of superficial velocities of water and inclination angles to flow patterns are negative (-0.07 and -0.13 , respectively), indicating that the relationship of these variables are of opposite directions, while the correlation coefficient between superficial velocities of air and flow regimes $(0.22)$ is positive, specifying that the values of both variables are developing in the same trend. The absolute values of correlation coefficients to flow pattern kept increasing in the order of superficial velocities of water, inclination angles, and superficial velocities of gas, indicating the level of significance of these features to flow regimes can be ranked in such an order within linear relationships. However, these values (between the range of -0.3 and 0.3 ) measured between flow pattern and input features indicate the linear relation assumption is less reliable. In reality, these variables are highly non-linearly related to flow patterns (see Fig. 1). On this account, a feature ranking method based on deep learning neural networks will be proposed in section 4.3 , taking in to account the nonlinear relationship between input features and flow pattern automatically. 


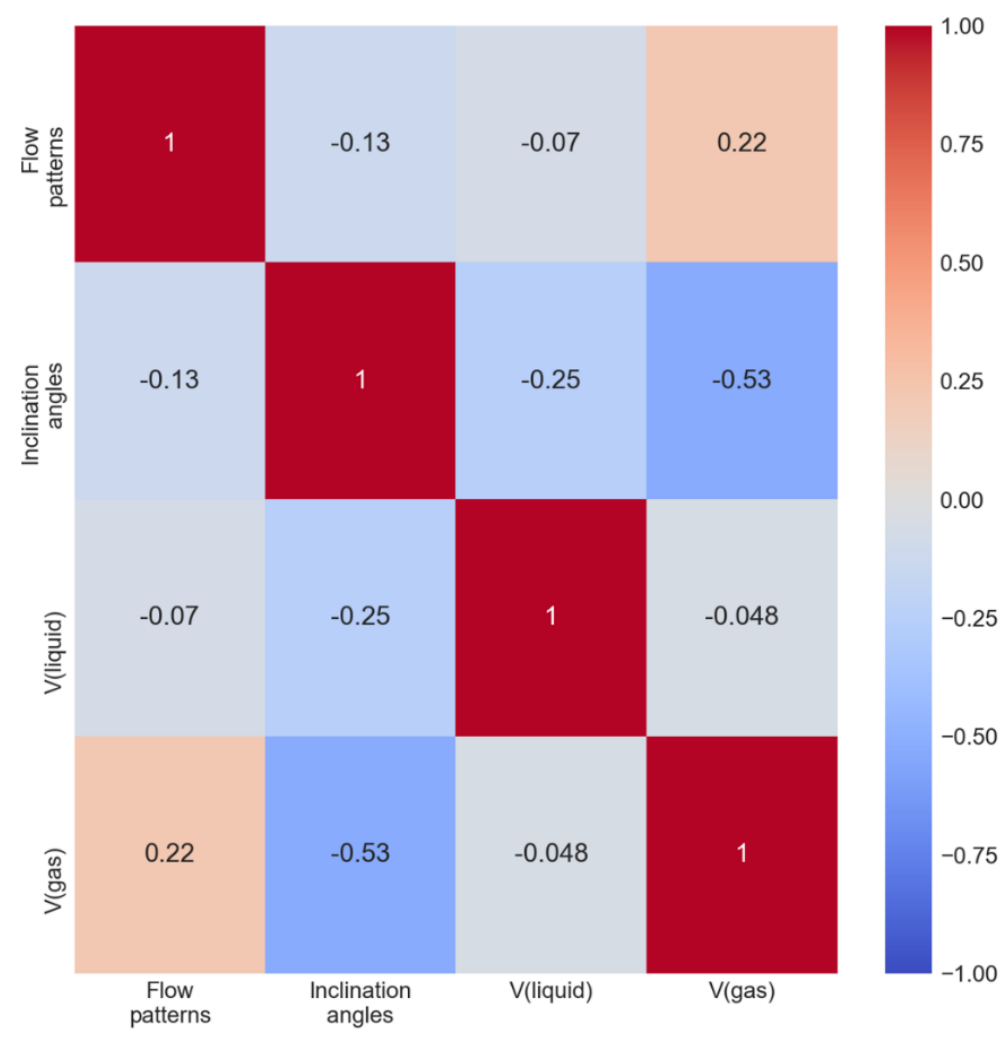

Fig. 2 - Heat map of features in the experimental datasets; note that, $\mathrm{V}$ (gas) is representing the superficial velocity of air and $\mathrm{V}$ (liquid) is representing the superficial velocity of water.

\section{Deep learning configurations}

One of the earliest studies of deep learning is presented by Hinton et al. [45], where the deep learning neural network method was initiated to recognise handwritten digits. Since then, this state-of-the-art technique is branched as "Deep Learning". Many investigators have concluded that deep learning was not only possible but capable of handling issues that no other machine learning algorithms could achieve. It has been widely applied in various energy topics, such as smart energy prediction [46], solar potential evaluation [47], and even electricity price forecasting [48]. In this study, a deep learning platform to identify flow patterns was realised through TensorFlow, which allows deep learning configurations to be performed and equipped based on large datasets with certain individual features. These features are usually consisting of multi-dimensional arrays, which are also considered as tensors in the model. Note that, as described in section 2.3, the observed flow pattern categories have been converted to numerical digitals before entering into the predictive model.

With very few exceptions, the deep learning algorithm wouldn't perform well while tensors are presented in different scales. Therefore, before features from experimental datasets flowing into the designed neural networks, the Min-Max scaler was applied to shrink features into the range between 0 and 1 . The corresponding formula can be expressed as: 


$$
X_{\text {scaled }}=\frac{x_{i}-\min (x)}{\max (x)-\min (x)}
$$

where $X_{\text {scaled }}$ is the normalized value; $x_{i}$ is the original value; $\min (x)$ and $\max (x)$ are the minimum and the maximum values in the span, respectively.

A visualised configuration of the proposed deep learning structure with emphasis on how tensors flow in various components is presented in Fig.3. To improve forecasting accuracy, several neural network structures were tested, including trials with various layers numbers and different neurons numbers in each layer. The final deep learning neural network consists of a five-layer structure ( see Fig.3, Layers $1 \sim 5$ ), creating the relationships between inputs (superficial velocities of water, superficial velocities of air, and inclination angles, see Fig.3, Input (a)) and outputs (flow patterns, see Fig.3, Output (g)). Both the first and the fifth layer have 50 neurons (see Fig.3, Layer 1 (b) \& Layer 5 (f)), while the remaining three layers have 20 neurons, respectively (see Fig.3, Layer 2 (c) Layer 4 (e)). In the deep learning neural network, all the five layers were connected by means of a computational graph, enabling tensors to flow from the first layer to the last one. A description of how each hidden layer functioned inside the deep learning model is presented using Layer 4 as an example (see Fig.3, Layer 4 (e)). There are three major components in the layer:

1) Weights for connections between each neuron, including the neurons in the previous layer, which represent the strength of the connections (see Fig.3 $\alpha$ ); weights initialization followed the Xavier algorithm, avoiding any overlarge or too small weights [49];

2) Biases for each neuron, which are realised by TensorFlow's built-in initializer, are used to regulate the output along with the weights to the neuron (see Fig.3ß);

3) An activation function was applied to yield the result of the current layer (see Fig.3r); it multiples the weights by input neurons and adds biases for deciding whether a neuron should be activated. In this paper, the Rectified Linear Unit (ReLU) were applied as the nonlinear-activation function. 


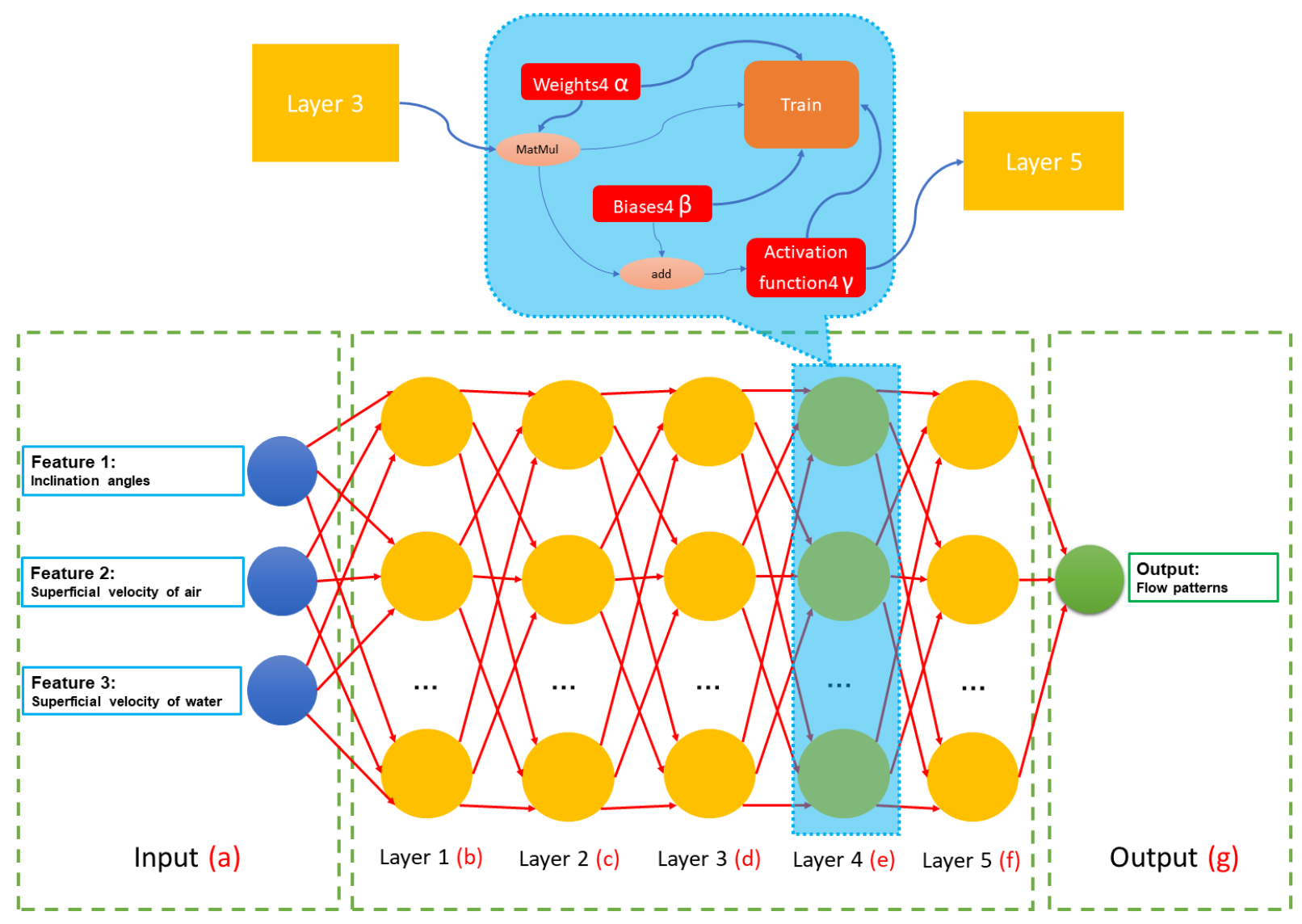

Fig. 3 - Visualization of the deep learning configuration.

The following correlations are implemented in each layer:

$$
H_{i}=\sum_{j=1}^{m} x_{i} w_{i j}+b_{j}
$$

where $H_{i}$ is the net input of neuron $\mathrm{j}$ in the deeper hidden layers or the output; $x_{i}$ is the input of neuron $\mathrm{j}$; $w_{i j}$ is the weights that connected neuron $\mathrm{i}$ and $\mathrm{j} ; b_{j}$ is the bias linked with neuron $\mathrm{j}$.

$$
h=\operatorname{ReLU}\left(H_{i}\right)=\max \left(0, H_{i}\right)
$$

where $h$ is the output of neuron $\mathrm{j}$.

For any machine learning algorithms, the predictive model not only needs to be trained but also requires a metrics to measure the accuracy of forecasting, which is referred to as a cost (or loss) function. To quantitively measure the difference between the predicted flow patterns and experimental observations, the Mean Square Error (MSE) forecast error criteria is used: 
$M S E=\frac{1}{n} \sum_{i=1}^{n}\left[\left(M_{\text {predicted }}\right)_{i}-\left(M_{\text {experimental }}\right)_{i}\right]^{2}$

where $n$ is the number of tests; $\left(M_{\text {predicted }}\right)_{i}$ and $\left(M_{\text {experimental }}\right)_{i}$ denotes the predicted value of the $i^{\text {th }}$ tensor from the deep learning model and the measured value of the $i^{\text {th }}$ tensor from the experimental datasets, respectively.

The experimental datasets were randomly divided into two groups - the training group with $80 \%$ data points and the testing group with $20 \%$ data points. The developed deep learning model follows a train-test-validation framework. First, the training phase was conducted by offering both input and output tensors to the predictive model while neural networks learn how to correlate input data to produce correct flow pattern forecasting. While the deep learning model has been trained, the independent testing data were applied to evaluate its forecasting ability. Once the constructed neural networks have been tested, the deep learning model was further validated via the conventional Barnea unified model [19] in the form of flow regime maps. Besides, the learning rate in the predictive model is set as 0.01 whereas the training and testing epochs are defined as 4000.

\section{Results and Discussions}

\subsection{Training and Testing}

As shown in Fig. 4, the MSE has displayed a rapid drop once the first a few hundreds of iterations were achieved, starting to reach convergency after 1000 around iterations. The stabilized MSE for training and testing data were 0.01497 and 0.01672 , respectively. The predicted flow patterns by the neural networks are compared with experimental observations recorded by Shoham [42] in Fig. 5, where a good agreement was achieved for all tested inclination angles. The performance of predictions for each flow pattern in the testing loop is presented in Table $\mathbf{3}$ in terms of accuracy. The classification accuracies in flow pattern prediction of stratified smooth, stratified wavy, annular, intermittent, and bubble flow are all above $90 \%$, with the exception of dispersed bubble flow. Dispersed bubble flow occurs while the velocity of water increases, where the bubbles are broken up into minor and separated bubbles. In our datasets, dispersed bubble flow arose only during high superficial water velocities (see Table 3). Therefore, corresponding data points of dispersed bubble flow only located at the "boundary" of the entire database. This may explain why the prediction accuracy of this flow pattern is relatively low (84\%). 


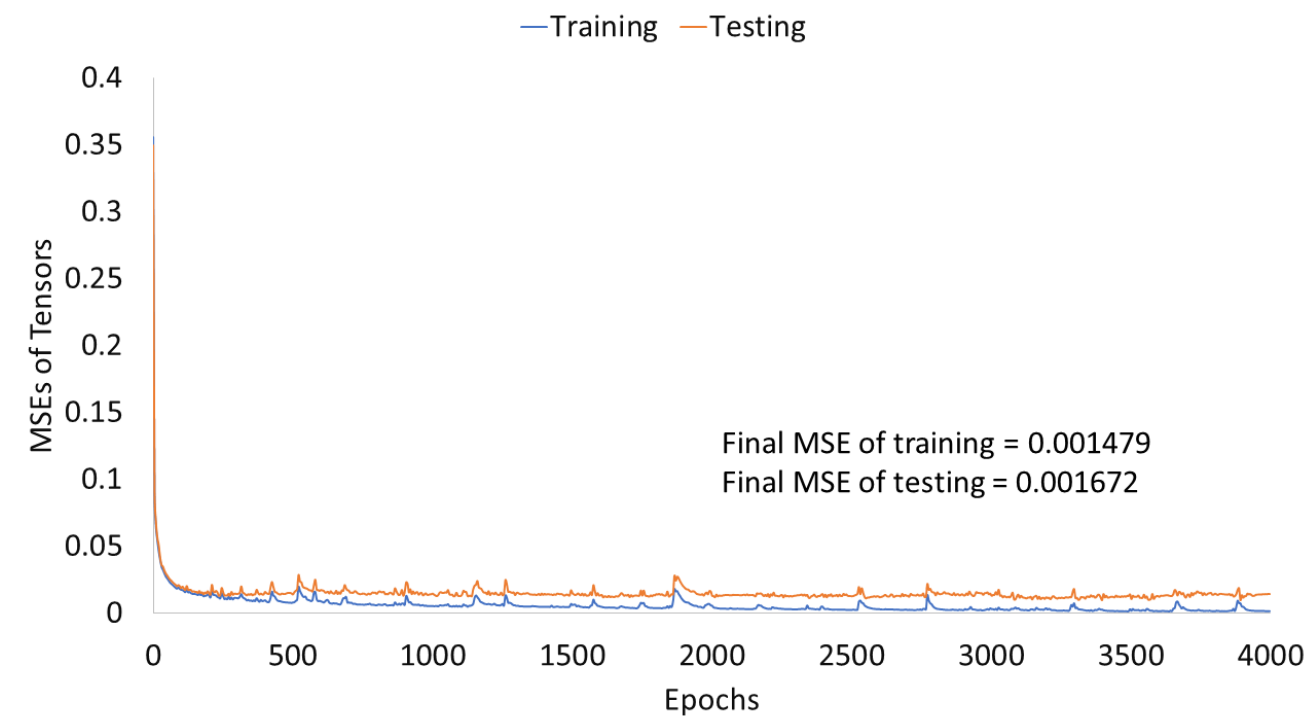

Fig. 4 - Variations of training and testing MSEs along 4000 epochs in the designed neural networks.

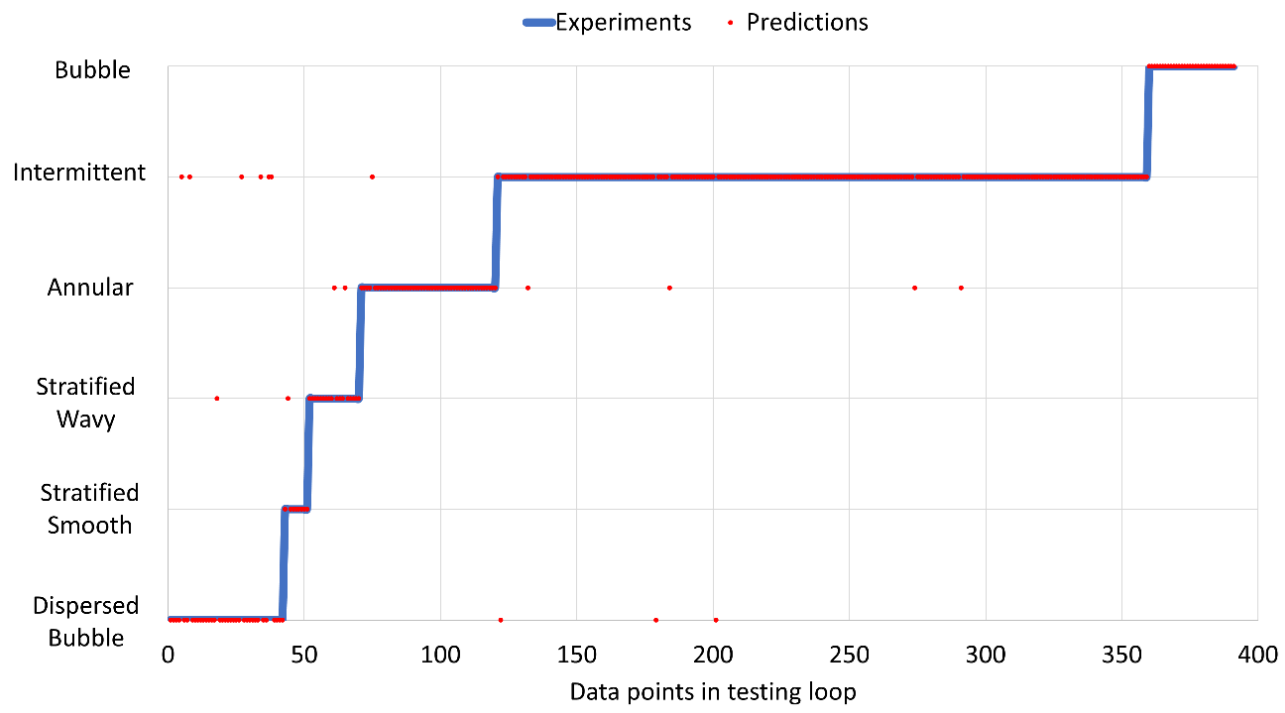

Fig. 5 - Comparison of flow pattern predictions between predictive model (dotted points) and experimental observations (full lines).

Table 3 - Accuracies of flow pattern prediction in the deep learning model.

\begin{tabular}{|c|c|c|c|c|}
\hline Flow Pattern & $\begin{array}{c}\text { Range of superficial } \\
\text { water velocities, } \mathrm{m} / \mathrm{s}\end{array}$ & $\begin{array}{c}\text { Range of superficial } \\
\text { air velocities, } \mathrm{m} / \mathrm{s}\end{array}$ & $\begin{array}{c}\text { Inclination } \\
\text { angles, }\end{array}$ & Accuracy, \% \\
\hline Dispersed Bubble & $2.02 \sim 6.3$ & $0.02 \sim 4$ & $0 \sim 90$ & 84 \\
\hline Stratified Smooth & $0.004 \sim 0.16$ & $0.025 \sim 4$ & 0 & 91 \\
\hline Stratified Wavy & $0.0025 \sim 0.063$ & $2.5 \sim 25$ & $0 \sim 10$ & 90 \\
\hline Annular & $0.0022 \sim 0.4$ & $8.72 \sim 40$ & $0 \sim 90$ & 98 \\
\hline Intermittent & $0.0022 \sim 4$ & $0.016 \sim 25$ & $0 \sim 90$ & 100 \\
\hline Bubble & $0.0022 \sim 1.54$ & $0.023 \sim 0.26$ & $70 \sim 90$ & \\
\hline
\end{tabular}

\subsection{Validation}


To further validate the reliability of the built deep learning model, it was compared with the predicted results from the unified model proposed by Barnea [19], which was designed for identifying flow regimes in the whole range of pipe inclinations by solving operative equations and consulting dimensionless maps. The detailed descriptions of the unified model can be found in Barnea's original research work [19]. As presented in Fig.6 10, comparisons are showed in the form of flow regime maps under inclination angles of $0^{\circ}, 1^{\circ}, 30^{\circ}, 80^{\circ}$, and $90^{\circ}$. Flow regime maps generated by the deep learning model are represented through dotted points while the results developed from the Barnea unified model are characterized by full lines. A great match was achieved between these two models, where the deep learning model happened to have the same point of view with the conclusions from Barnea [19]. For instance, in the deep learning flow regime maps, the stratified smooth flow could only be observed under inclination angles that are close or equal to $0^{\circ}$ (see Fig. 6); dispersed bubble, annular, and intermittent flows were observed in the entire range of upward inclinations (see Fig.6 10); the stratified wavy flow could only be observed in horizontal or near-horizontal flows (see Fig. 6 and 7) while bubble flow could only be identified in vertical or near-vertical flows (see Fig. 9 and 10). In Fig. 7, there are obvious differentials between the predicted stratified wavy flows from the deep learning model and the results from the Barnea unified model. It is encouraging to compare this phenomenon with what was found by Barnea [19], where similar differentials were observed when the Barnea unified model was compared with corresponding experimental results. This can be another evidence, indicating the predictions of deep learning are closer to the actual experimental observations.

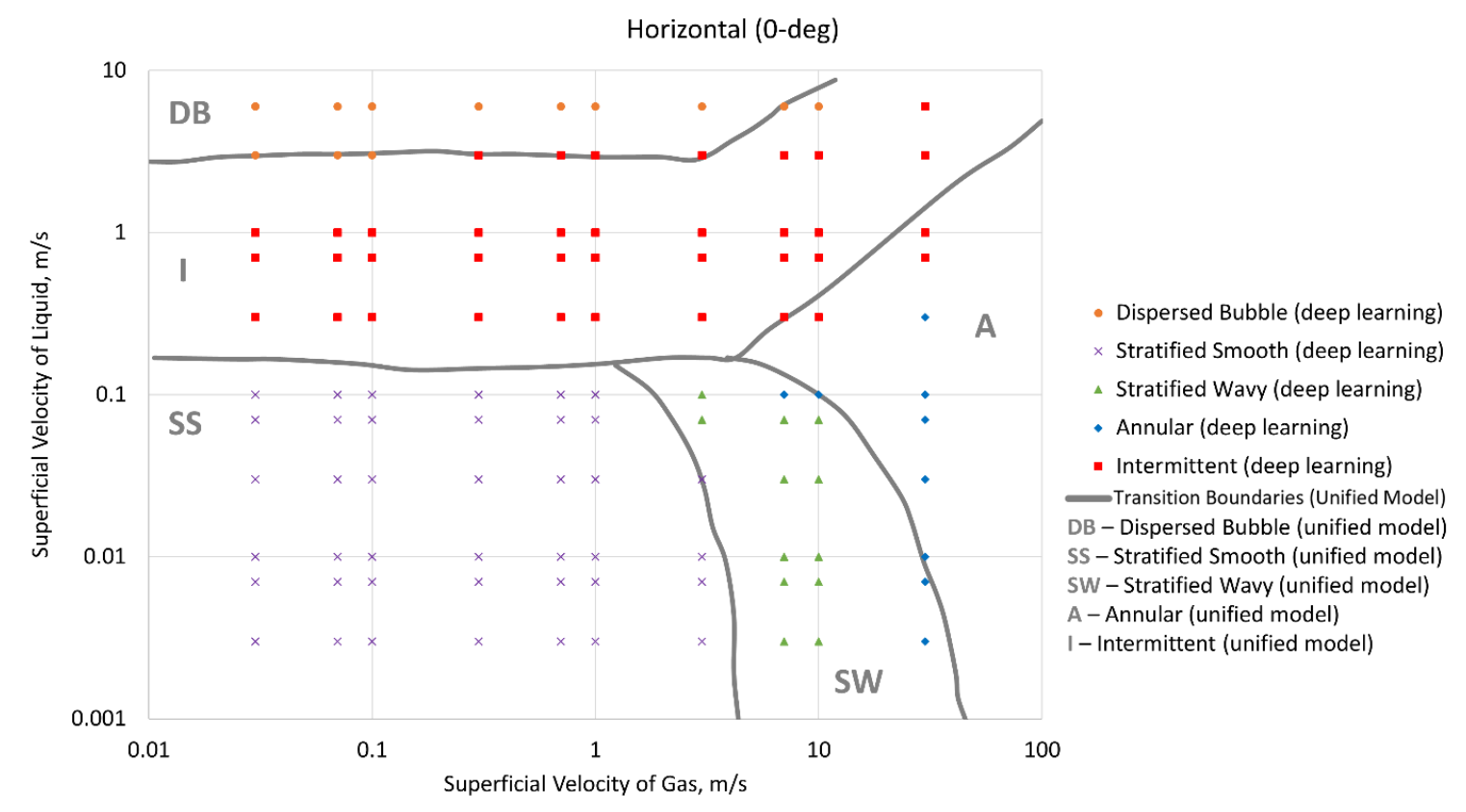

Fig. 6 - Comparisons of flow regime maps generated by deep learning model (dotted points) and unified model (full lines) for two-phase flow in horizontal $\left(0^{\circ}\right)$ pipe. 


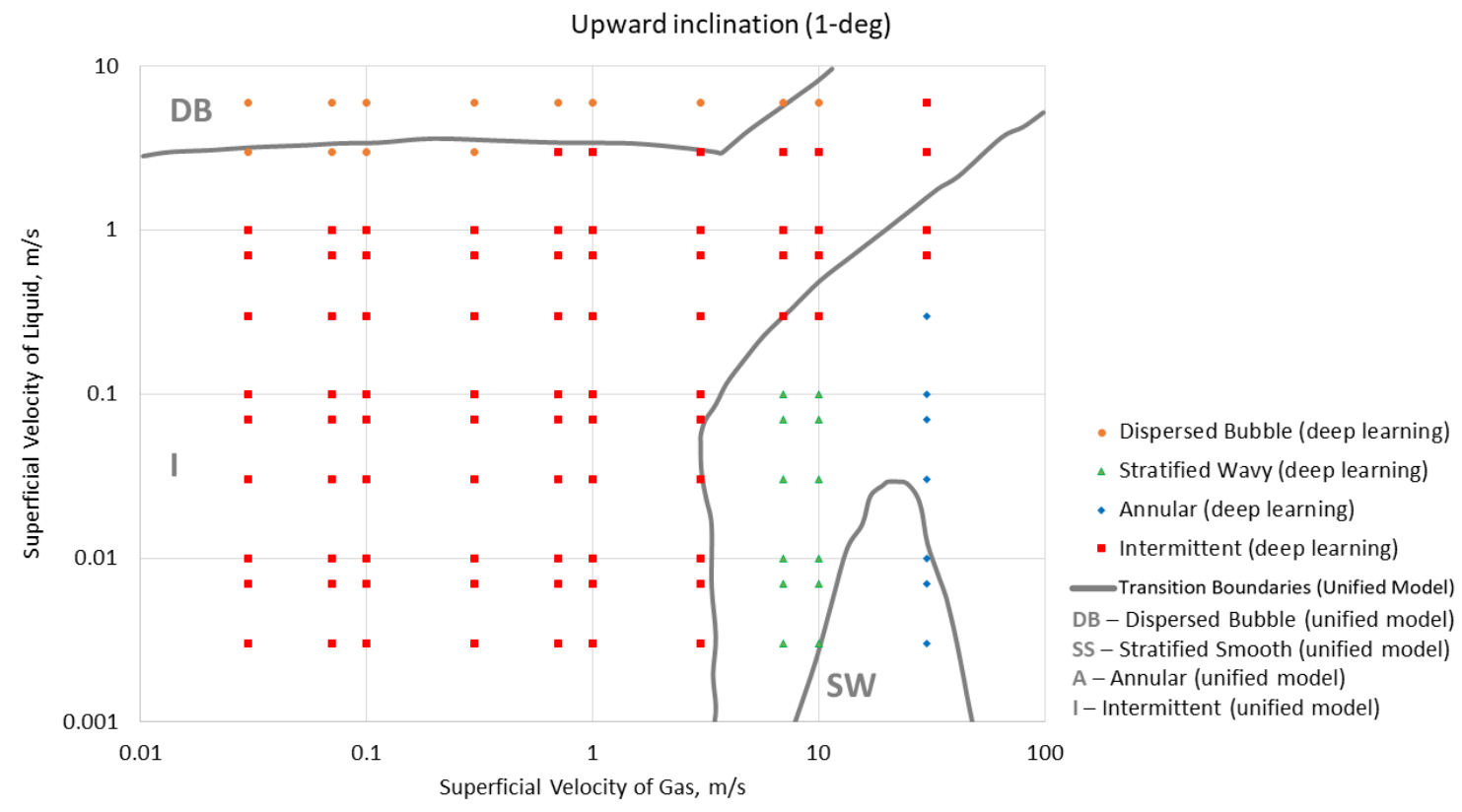

Fig. 7 - Comparisons of flow regime maps generated by deep learning model (dotted points) and unified model (full lines) for two-phase flow in upward inclined $\left(1^{\circ}\right)$ pipe.

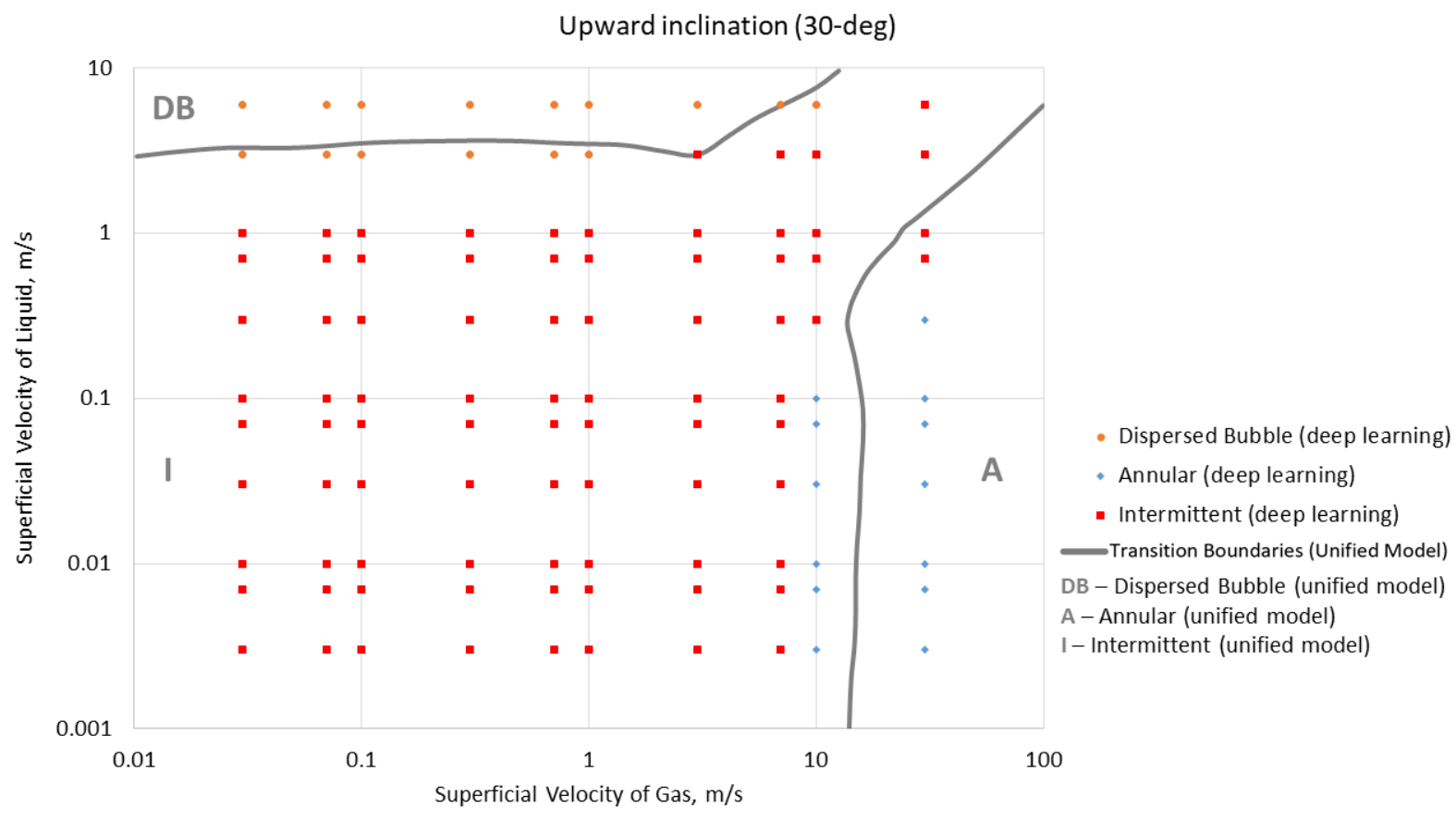

Fig. 8 - Comparisons of flow regime maps generated by deep learning model (dotted points) and unified model (full lines) for two-phase flow in upward inclined $\left(30^{\circ}\right)$ pipe. 


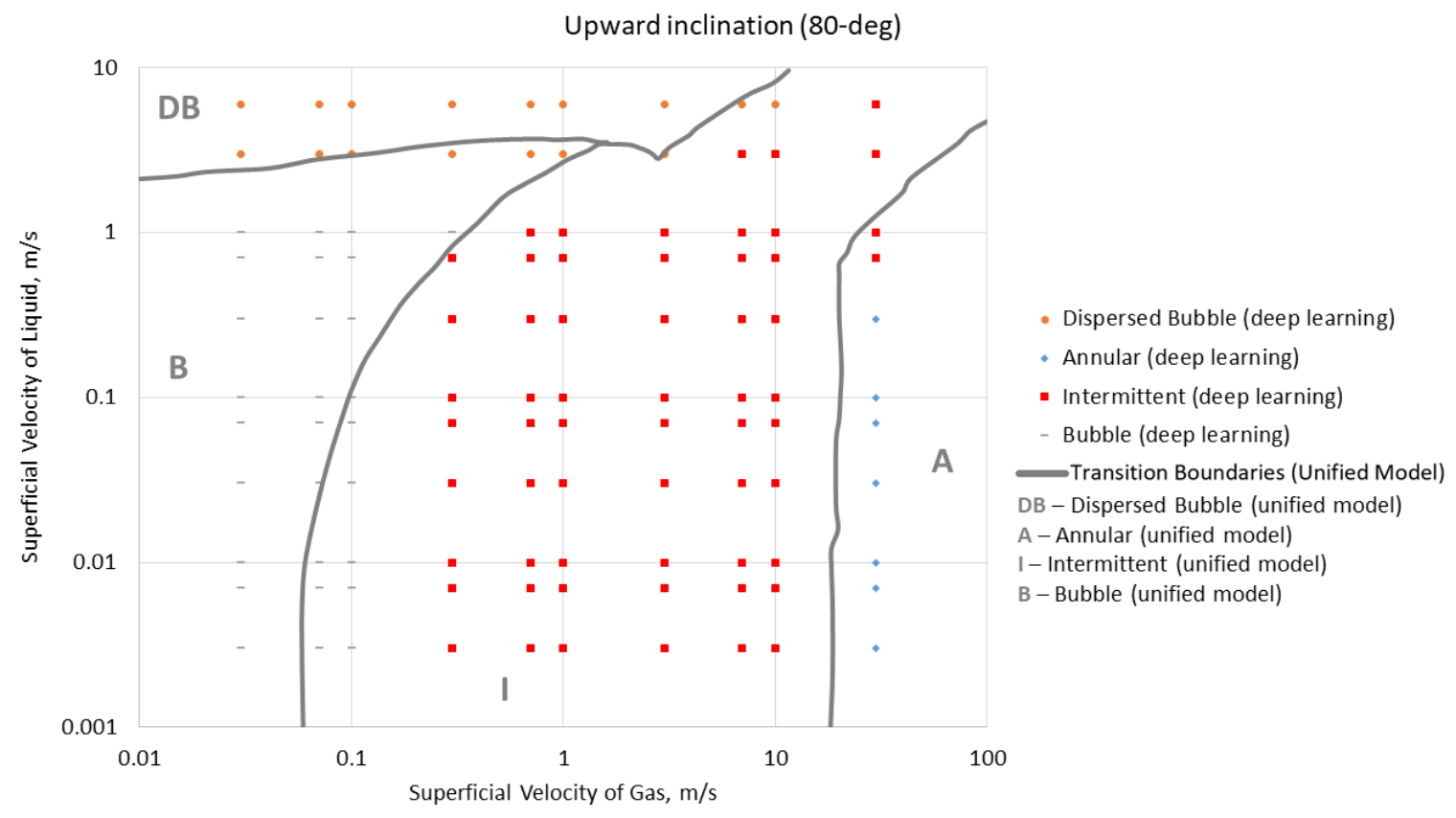

Fig. 9 - Comparisons of flow regime maps generated by deep learning model (dotted points) and unified model (full lines) for two-phase flow in upward inclined $\left(80^{\circ}\right)$ pipe.

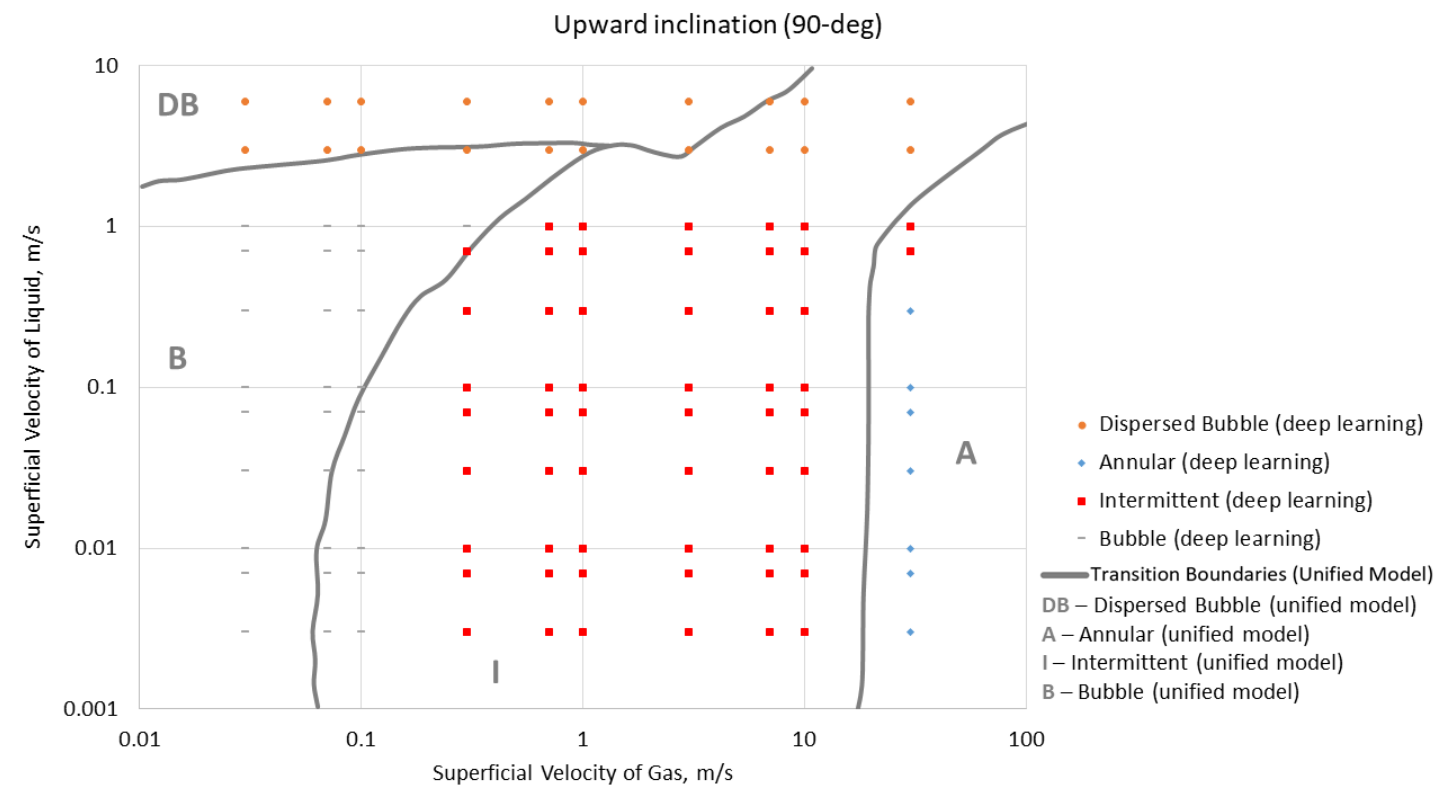

Fig. 10 - Comparisons of flow regime maps generated by deep learning model (dotted points) and unified model (full lines) for two-phase flow in vertical $\left(90^{\circ}\right)$ pipe.

Conventional correlations used in flow pattern prediction usually required certain factors that are needed to be entered into the equations. For instance, in the Barnea unified model, the correlation of stratified and annular flow involved the friction factor at the water-air interface. This factor is a typical empirical parameter, which is hard to be measured or recorded. One of 
the major advantages of the currently proposed methodology is that its input variables are easily accessible, which make it more applicable in industries.

\subsection{Feature significance}

The feature importance in the built deep learning model was also examined, ranking the level of significance between input features and the predicted flow patterns. The ranking of the top-rated features was determined using the variations of the final MSEs in the predictive model. More specifically, at each testing loop, one feature was substituted by its average value, while other parameters/structures remained the same in the deep learning model. As only one feature is replaced at one time, this assessment will be reiterated on all the three inputs one by one, including superficial velocities of water, superficial velocities of gas, and inclination angles. Changes of MSEs along testing loops over each feature are presented in Fig. 11. Comparing with the initial circumstance, the values of the final MSEs kept increasing in the order of inclination angles $($ MSE $=0.03110)$, superficial velocities of gas $(\mathrm{MSE}=0.04952)$, and superficial velocities of water $(\mathrm{MSE}=0.08487)$, indicating the level of importance of features in flow pattern prediction can be ranked in such an order. Contrasting to correlation coefficients that were presented in section 2.3, the correlations between features and flow patterns have been reset. The current conclusions based on feature importance are respected to be more rigid, where non-linear relationships were considered between features and the output flow patterns, unlike the linear coefficients. As superficial velocities of water \& air govern most flow parameters that are of interest to field applications, they are self-evidently significant for flow pattern identification. Therefore, superficial velocities took the first two places in the level of significance. Even the impact of inclined angles on flow pattern identification is ranked as the third, it still approximately doubled the final MSE values from 0.01672 to 0.03110 when this feature is not considered, significantly reducing the accuracy of the predictive model. 


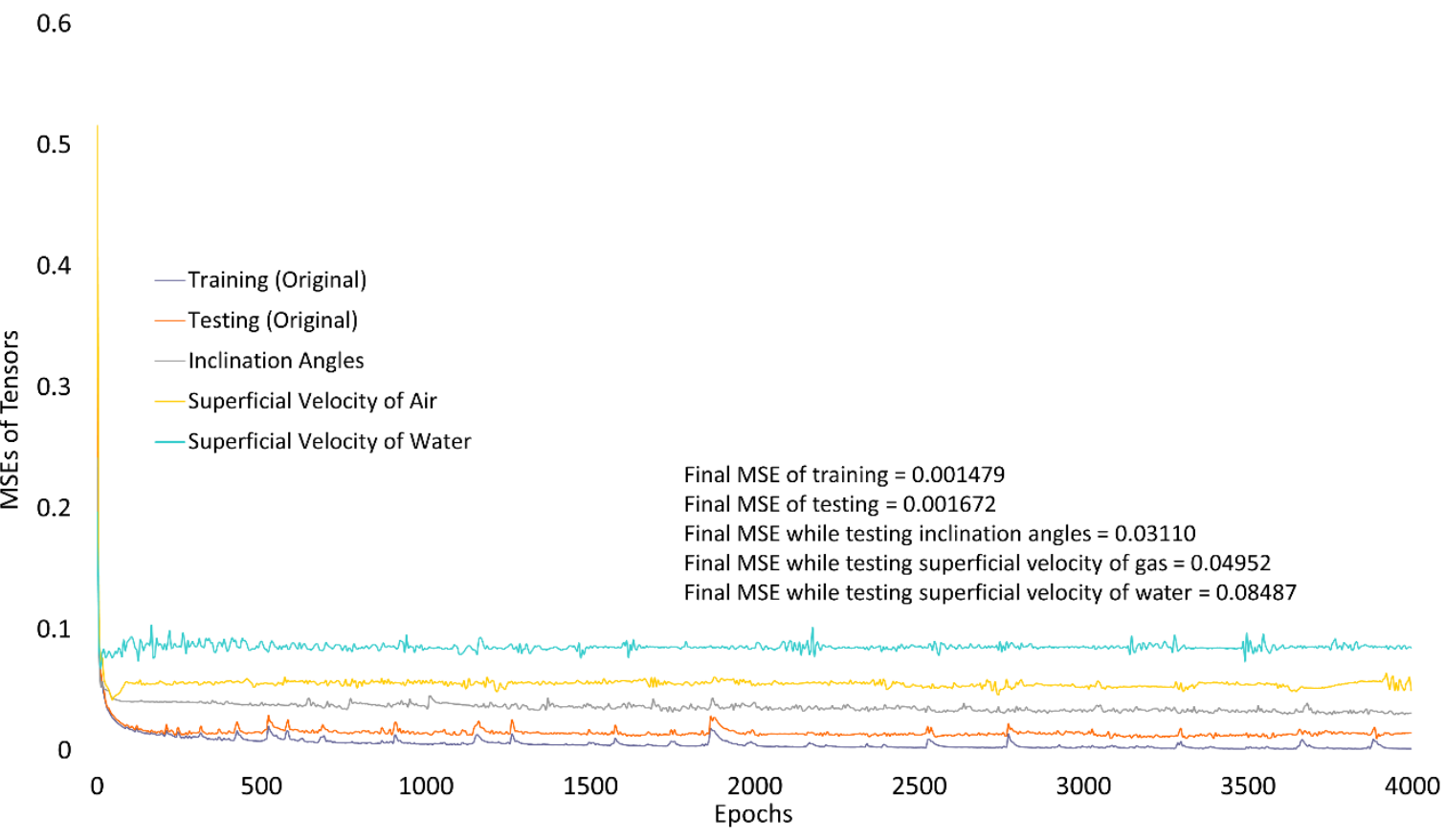

Fig. 11 - Variations MSEs in the deep learning configuration under varying input features.

\section{Conclusions}

This work contributes to knowledge gaps in flow pattern identification by developing an integrated methodology to identify and predict two-phase flow patterns through deep learning neural networks, which were trained, tested and validated through experimental datasets and well-established flow regime maps. The key strength of this study is that it represents a comprehensive investigation of flow regime transitions in vertical, horizontal, and varying upward inclined pipes through deep learning predictive model. Based on the facts above, the findings from this study makes several noteworthy contributions:

- This paper successfully constructed a deep learning neural network model to predict flow patterns in two-phase flows while upward inclined angles varied from $0^{\circ}$ to $90^{\circ}$. Unlike traditional correlations, the developed method represents a breakthrough in the way of flow pattern identification using accessible parameters of superficial velocities of air \& water and inclined angles as inputs. The integrated deep learning framework, therefore, assists in the design \& analysis of flow loops with arbitrary inclination angles in energy systems.

- The designed deep learning model has been evaluated against experimental observations. The comparison results suggested that the present model has high accuracy in flow pattern identification. The accuracies of predictions in stratified smooth, stratified wavy, annular, intermittent, and bubble flow are all above $90 \%$. The only exception occurred in dispersed bubble flow identification with the accuracy of prediction of $84 \%$, due to most data points of this flow pattern were located at the boundary of the datasets. 
- Flow regime maps that were generated from the deep learning neural networks were further compared and validated by the widely accepted Barnea unified model, where a great match was achieved between these two approaches. Besides, based on the results of comparisons, the flow regime maps developed from the current study fit better with experimental observations.

- This research has demonstrated, for the first time, the level of significance of input features to quantitively evaluate flow patterns via deep learning. This approach expands our understanding of how different features will determine the accuracy in flow pattern identification through nonlinear analysis, showing more reliable results than the commonly used correlation coefficients. Compared to fixed flow conditions, variations of inclination angles have a significant influence on gas-liquid flow patterns in channels of conventional sizes.

\section{References}

[1] Lun I, Calay RK, Holdo AE. Modelling two-phase flows using CFD. Applied Energy 1996;53:299-314. https://doi.org/10.1016/0306-2619(95)00024-0.

[2] Andersson M, Beale SB, Espinoza M, Wu Z, Lehnert W. A review of cell-scale multiphase flow modeling, including water management, in polymer electrolyte fuel cells. Applied Energy 2016;180:757-78. https://doi.org/10.1016/j.apenergy.2016.08.010.

[3] Liu C, Li Z, Zeng L, Zhang Q, Hu R, Zhang X, et al. Gas/particle two-phase flow characteristics of a down-fired 350 MWe supercritical utility boiler at different tertiary air ratios. Energy 2016;102:54-64. https://doi.org/10.1016/j.energy.2016.02.016.

[4] Miliauskas G, Maziukienè M, Jouhara H, Poškas R. Investigation of mass and heat transfer transitional processes of water droplets in wet gas flow in the framework of energy recovery technologies for biofuel combustion and flue gas removal. Energy 2019;173:740-54. https://doi.org/10.1016/j.energy.2019.02.101.

[5] Ashrafi M, Kanani H, Shams M. Numerical and experimental study of two-phase flow uniformity in channels of parallel PEM fuel cells with modified Z-type flow-fields. Energy 2018;147:317-28.

https://doi.org/10.1016/j.energy.2018.01.064.

[6] Yin C, Gao J, Wen X, Xie G, Yang C, Fang H, et al. In situ investigation of proton exchange membrane fuel cell performance with novel segmented cell design and a two-phase flow model. Energy 2016;113:1071-89. https://doi.org/10.1016/j.energy.2016.06.097.

[7] Falcone G, Liu X, Okech RR, Seyidov F, Teodoriu C. Assessment of deep geothermal energy exploitation methods: The need for novel single-well solutions. Energy 2018;160:54-63.

https://doi.org/https://doi.org/10.1016/j.energy.2018.06.144.

[8] Liu X, Falcone G, Alimonti C. A systematic study of harnessing low-temperature geothermal energy from oil and gas reservoirs. Energy 2018;142. https://doi.org/10.1016/j.energy.2017.10.058.

[9] Lin Z, Liu X. Wind power forecasting of an offshore wind turbine based on high-frequency SCADA data and deep learning neural network. Energy 2020. https://doi.org/https://doi.org/10.1016/j.energy.2020.117693.

[10] Lin Z, Liu X. Assessment of wind turbine aero-hydro-servo-elastic modelling on the effects of mooring line tension via deep learning. Energies 2020;13:2264.

[11] Wu Y, Ke Y, Zhang T, Liu F, Wang J. Performance efficiency assessment of photovoltaic poverty alleviation projects in China: A three-phase data envelopment analysis model. Energy 2018;159:599-610. https://doi.org/10.1016/j.energy.2018.06.187.

[12] Liu X, Lao L, Falcone G. A comprehensive assessment of correlations for two-phase flow through Venturi tubes. Journal of Natural Gas Science and Engineering 2020;78:103323. https://doi.org/https://doi.org/10.1016/j.jngse.2020.103323.

[13] Ayati AA, Kolaas J, Jensen A, Johnson GW. A PIV investigation of stratified gas-liquid flow in a horizontal pipe. International Journal of Multiphase Flow 2014;61:129-43. https://doi.org/https://doi.org/10.1016/j.ijmultiphaseflow.2014.01.008. 
[14] Tang P, Yang J, Zheng J, Wong I, He S, Ye J, et al. Failure analysis and prediction of pipes due to the interaction between multiphase flow and structure. Engineering Failure Analysis 2009;16:1749-56.

https://doi.org/https://doi.org/10.1016/j.engfailanal.2009.01.002.

[15] Tsutsumi A, Kikuchi R. Design and scale-up methodology for multi-phase reactors based on non-linear dynamics. Applied Energy 2000;67:195-219. https://doi.org/10.1016/S0306-2619(00)00014-3.

[16] G.F. HEWITT and N.S. HALL-TAYLOR. Annular Two-Phase Flow. Elsevier Ltd; 1970. https://doi.org/https://doi.org/10.1016/C2009-0-06773-7.

[17] Taitel Y, Bornea D, Dukler AE. Modelling flow pattern transitions for steady upward gas-liquid flow in vertical tubes. AIChE Journal 1980;26:345-54. https://doi.org/10.1002/aic.690260304.

[18] Barnea D, Shoham O, Taitel Y, Dukler AE. Flow pattern transition for gas-liquid flow in horizontal and inclined pipes. Comparison of experimental data with theory. International Journal of Multiphase Flow 1980;6:217-25. https://doi.org/10.1016/0301-9322(80)90012-9.

[19] Barnea D. A unified model for predicting transitions for the whole pipe inclinations. International Journal of Multiphase Flow 1987;13:1-12.

[20] Barnea D, Shoham O, Taitel Y. Flow pattern characterization in two phase flow by electrical conductance probe. International Journal of Multiphase Flow 1980;6:387-97. https://doi.org/10.1016/0301-9322(80)90001-4.

[21] Oddie G, Shi H, Durlofsky LJ, Aziz K, Pfeffer B, Holmes JA. Experimental study of two and three phase flows in large diameter inclined pipes. International Journal of Multiphase Flow 2003;29:527-58. https://doi.org/10.1016/S0301-9322(03)00015-6.

[22] Zhang H-Q, Wang Q, Sarica C, Brill JP. Unified Model for Gas-Liquid Pipe Flow via Slug Dynamics—Part 1: Model Development. Journal of Energy Resources Technology 2003;125:266. https://doi.org/10.1115/1.1615246.

[23] Zhang H-Q, Wang Q, Sarica C, Brill JP. Unified Model for Gas-Liquid Pipe Flow via Slug Dynamics—Part 2: Model Validation. Journal of Energy Resources Technology 2003;125:274. https://doi.org/10.1115/1.1615618.

[24] Nnabuife SG, Pilario KES, Lao L, Cao Y, Shafiee M. Identification of Gas-Liquid Flow Regimes Using a Nonintrusive Doppler Ultrasonic Sensor and Virtual Flow Regime Maps. Flow Measurement and Instrumentation 2019;68. https://doi.org/10.1016/j.flowmeasinst.2019.05.002.

[25] Wiedemann P, Döß A, Schleicher E, Hampel U. Fuzzy flow pattern identification in horizontal air-water two-phase flow based on wire-mesh sensor data. International Journal of Multiphase Flow 2019;117:153-62. https://doi.org/10.1016/j.ijmultiphaseflow.2019.05.004.

[26] Cai S, Toral H, Qiu J, Archer JS. Neural network based objective flow regime identification in air-water two phase flow. The Canadian Journal of Chemical Engineering 1994;72:440-5. https://doi.org/10.1002/cjce.5450720308.

[27] Hernández L, Juliá JE, Chiva S, Paranjape S, Ishii M. Fast classification of two-phase flow regimes based on conductivity signals and artificial neural networks. Measurement Science and Technology 2006;17:1511-21. https://doi.org/10.1088/0957-0233/17/6/032.

[28] Rosa ES, Salgado RM, Ohishi T, Mastelari N. Performance comparison of artificial neural networks and expert systems applied to flow pattern identification in vertical ascendant gas-liquid flows. International Journal of Multiphase Flow 2010;36:738-54. https://doi.org/10.1016/j.ijmultiphaseflow.2010.05.001.

[29] Santoso B, Indarto, Deendarlianto, Thomas SW. The identification of gas-liquid co-current two phase flow pattern in a horizontal pipe using the power spectral density and the artificial neural network (ANN). Modern Applied Science 2012;6:56-67. https://doi.org/10.5539/mas.v6n9p56.

[30] Ghosh S, Pratihar DK, Maiti B, Das PK. Identification of flow regimes using conductivity probe signals and neural networks for counter-current gas-liquid two-phase flow. Chemical Engineering Science 2012;84:417-36. https://doi.org/10.1016/j.ces.2012.08.042.

[31] Figueiredo MMF, Goncalves JL, Nakashima AMV, Fileti AMF, Carvalho RDM. The use of an ultrasonic technique and neural networks for identification of the flow pattern and measurement of the gas volume fraction in multiphase flows. Experimental Thermal and Fluid Science 2016;70:29-50. https://doi.org/10.1016/j.expthermflusci.2015.08.010.

[32] Abbagoni BM, Yeung H. Non-invasive classification of gas-liquid two-phase horizontal flow regimes using an ultrasonic Doppler sensor and a neural network. Measurement Science and Technology 2016;27. https://doi.org/10.1088/0957-0233/27/8/084002.

[33] Hanus R, Zych M, Kusy M, Jaszczur M, Petryka L. Identification of liquid-gas flow regime in a pipeline using gamma-ray absorption technique and computational intelligence methods. Flow Measurement and Instrumentation 2018;60:17-23. https://doi.org/10.1016/j.flowmeasinst.2018.02.008.

[34] Casari A, Zheng A. Feature Engineering for Machine Learning. 2018.

[35] Ghadimi N, Akbarimajd A, Shayeghi H, Abedinia O. Two stage forecast engine with feature selection technique and improved meta-heuristic algorithm for electricity load forecasting. Energy 2018;161:130-42. https://doi.org/https://doi.org/10.1016/j.energy.2018.07.088. 
[36] McQuillan KW, Whalley PB. Flow patterns in vertical two-phase flow. International Journal of Multiphase Flow 1985;11:161-75. https://doi.org/10.1016/0301-9322(85)90043-6.

[37] Haida M, Smolka J, Hafner A, Mastrowski M, Palacz M, Madsen KB, et al. Numerical investigation of heat transfer in a CO2 two-phase ejector. Energy 2018;163:682-98. https://doi.org/10.1016/j.energy.2018.08.175.

[38] Xie J, Xu J, Liang C, She Q, Li M. A comprehensive understanding of enhanced condensation heat transfer using phase separation concept. Energy 2019;172:661-74. https://doi.org/10.1016/j.energy.2019.01.134.

[39] Liu W, Wu Z, Li J, Zheng J, Li Y. The seepage characteristics of methane hydrate-bearing clayey sediments under various pressure gradients. Energy 2019;191:116507. https://doi.org/10.1016/j.energy.2019.116507.

[40] Wang M, Rahimi M, Kumar A, Hariharan S, Choi W, Hatton TA. Flue gas CO2 capture via electrochemically mediated amine regeneration: System design and performance. Applied Energy 2019;255:113879. https://doi.org/10.1016/j.apenergy.2019.113879.

[41] Pereyra E, Torres C, Mohan R, Gomez L, Kouba G, Shoham O. A methodology and database to quantify the confidence level of methods for gas - liquid two-phase flow pattern prediction. Chemical Engineering Research and Design 2011;90:507-13. https://doi.org/10.1016/j.cherd.2011.08.009.

[42] Shoham O. Flow Pattern Transitions and Characterization in Gas-Liquid Two-Phase Flow in Inclined Pipes (PhD Dissertation). 1982.

[43] Mu Y, Liu X, Wang L. A Pearson's correlation coefficient based decision tree and its parallel implementation. Information Sciences 2018;435:40-58. https://doi.org/https://doi.org/10.1016/j.ins.2017.12.059.

[44] Ratner B. The correlation coefficient: Its values range between $+1 /-1$, or do they? Journal of Targeting, Measurement and Analysis for Marketing 2009;17:139-42.

[45] Hinton GE, Osindero S, Teh YW. A fast learning algorithm for deep belief nets. Neural Computation 2006;18:152754. https://doi.org/10.1162/neco.2006.18.7.1527.

[46] Ahmad T, Chen H. Deep learning for multi-scale smart energy forecasting. Energy 2019;175:98-112. https://doi.org/10.1016/j.energy.2019.03.080.

[47] Wen L, Zhou K, Yang S, Lu X. Optimal load dispatch of community microgrid with deep learning based solar power and load forecasting. Energy 2019;171:1053-65. https://doi.org/10.1016/j.energy.2019.01.075.

[48] Chang Z, Zhang Y, Chen W. Electricity price prediction based on hybrid model of adam optimized LSTM neural network and wavelet transform. Energy 2019;187:115804. https://doi.org/10.1016/j.energy.2019.07.134.

[49] Aydiner C, Demir I, Yildiz E. Modeling of flux decline in crossflow microfiltration using neural networks: The case of phosphate removal. Journal of Membrane Science 2005;248:53-62. https://doi.org/10.1016/j.memsci.2004.07.036. 